\title{
Control of a biomass combustor using the general SMITH PREDICTOR
}

\author{
R. Ramírez¹ \& A. Aguado² \\ ${ }^{1}$ CIATEQ (México) \\ E-mail: raulrmzl@ieee.org \\ ${ }^{2}$ ICIMAF (Cuba) \\ E-mail: aguado9941@yahoo.es
}

Received: May $4^{\text {th }} 2001$ and accepted March $5^{\text {th }} 2002$

\begin{abstract}
This paper proposes a modification to the classic Smith Predictor, known since several decades as an effective control method for the pure delay noxious effect in the control loop systems. The modification consists in the use of a high order model for the system, using an idea of Strejc, instead of the first order model with delay as was proposed by Smith. This allows better approximation to high order systems. It is presented an algorithm to calculate the Strejc model of the system to be controlled, based on itsrespons to a unit step disturb.
\end{abstract}

\section{RESUMEN}

Este trabajo propone una modificación al clásico Predictor de Smith, conocido desde hace variasdécadas como un método de control muy efectivo para contrarrestar el efecto nocivo del retardo puro en loslazosde control. La modificación consiste en el uso de un modelo de alto orden para el sistema, usando una idea de Strejc, en lugar del modelo de primer orden con retardo propuesto Smith. Esto permite una mejor aproximación para procesos de alto orden. Se presenta un algoritmo para calcular el modelo de Strejcdel sistema a controlar, a partir de la respuesta a una perturbación en forma de escalón.

KEYWORDS: Biomass Combustor, Control, Smith Predictor.

\section{INTRODUCTION}

Factors that affects enormously the performance and stability of a control system, either basedupona PID algorithm or any other, is the presence of a transportation delay or delay in the control loop. Many solutions have been tried in order to compensate the negative effect of the delay. Among these solutions, the Smith Predictor [1, 3, 4], know $n$ since the end of the 50's, is specially useful due to its simplicity and effectiveness. The generalized use of this concept, how ever, had a difficulty in its implementation using the analogous technology available in the 50's and 60's. Today, with the extensive use of the digital techniques in control, the Smith Predictor has more popularity and validity, resulting in an excellent alternative among sophisticated and complex predictive control methods.

The Smith Predictor supposes, in its original form, that the system to be controlled is modeled througha first order transfer function w ith a delay. This model works properly in many practical cases, even if the process to be controlled has a higher order: second or third order, for instance. Nevertheless, the resulting control system performance diminishes as the order increases. As a consequence, it is useful to have a different model than the proposed by Smith. This other model should produce more exact predictions of the output, without increasing the cost of complexity in the identification or even in the 
control process. In order to obtain the proposed result, it should be remembered another classical result of the 60's decade: the Strejc method [2] to approximate continuous transfer functions though a model $w$ ith only one time constant repeated $n$ times, starting out $w$ ith the unit step response of the process. This model obviously has more possibilities to approach the real system output than the Smith one. How ever, this method w orks out w ith the graphics of the unit step response of the system in which it is necessary the visual detection of the inflexion point. This procedure is very tedious and inaccurate. One of the objectives of this w ork is to find an algorithm for the automatic detection of the inflexion point, so that the required values can be calculated from the Strejc tables.

The next section exposes in detail the procedure in order to determine automatically the Strejc model starting out $w$ ith the unit step response of the process. The results obtained $w$ ith this procedure are show $\mathrm{n}$ by some simulations and by a real system application.

\section{STREJC METHOD}

This method [2] is based upon the graphical construction presented in figure 1, w hich represents the unit step response of a high order system.

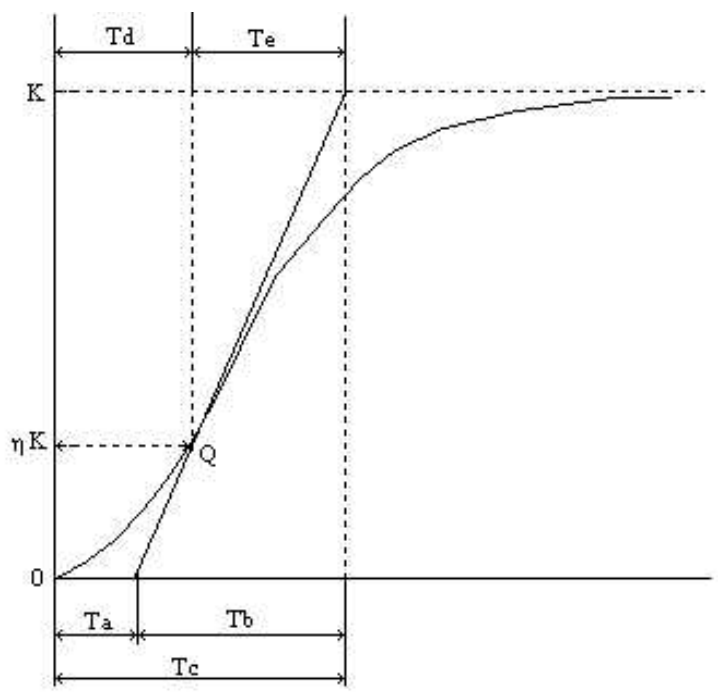

Figure 1. Unit step response of a system and the necessary parameters to approach it by a Strejc-type function.

Accordingly to Strejc, a non-periodic system $w$ ith $n$ different time constants can be approximated by a transfer function that represents $n$ identical time constants, i. e.:

$$
G(s)=\frac{K}{\left(T_{1} s+1\right)\left(T_{2} s+1\right) \ldots\left(T_{n} s+1\right)} \cong \frac{K}{(\tau s+1)^{n}}
$$

where $K$ represents the stationary state gain. The identification problem is then reduced to estimate the parameters $\tau$ and $n$. With this goal, the author of the method tabulated the relations betw een $n$ and the quotients $T a / T b$ y $T e / T b$, show $n$ in the Table I. Once the order $n$ has been determined $w$ ith $T a / T b$ and verified w ith $T e / T b$, the equivalent time constant $\tau$ can be obtained $w$ ith $T a / \tau$, and verified with theother relations $T b / \tau, T d / \tau$ y $T e / \tau$ given in Table II. 
Table I. Relation between the order $N$ and the parameters $T a / T b, T e / T b$, and $\eta$

\begin{tabular}{|l|l|l|l|l|l|l|l|l|l|l|}
\hline $\mathbf{N}$ & $\mathbf{1}$ & $\mathbf{2}$ & $\mathbf{3}$ & $\mathbf{4}$ & $\mathbf{5}$ & $\mathbf{6}$ & $\mathbf{7}$ & $\mathbf{8}$ & $\mathbf{9}$ & $\mathbf{1 0}$ \\
\hline $\mathbf{T a} / \mathbf{T b}$ & 0 & 0.104 & 0.218 & 0.319 & 0.410 & 0.493 & 0.570 & 0.642 & 0.709 & 0.773 \\
\hline $\mathbf{T e} / \mathbf{T b}$ & 1 & 0.736 & 0.677 & 0.647 & 0.629 & 0.616 & 0.606 & 0.599 & 0.593 & 0.587 \\
\hline$\eta$ & 0 & 0.264 & 0.323 & 0.353 & 0.371 & 0.384 & 0.394 & 0.401 & 0.407 & 0.413 \\
\hline
\end{tabular}

Table II. Relation between the order $N$ and the parameters $T a / \tau, T b / \tau, T d / \tau$ and $T e / \tau$.

\begin{tabular}{|l|l|l|l|l|l|l|l|l|l|l|}
\hline $\boldsymbol{n}$ & $\mathbf{1}$ & $\mathbf{2}$ & $\mathbf{3}$ & $\mathbf{4}$ & $\mathbf{5}$ & $\mathbf{6}$ & $\mathbf{7}$ & $\mathbf{8}$ & $\mathbf{9}$ & $\mathbf{1 0}$ \\
\hline $\mathbf{T a} / \tau$ & 0 & 0.282 & 0.805 & 1.425 & 2.1 & 2.811 & 3.549 & 4.307 & 5.081 & 5.869 \\
\hline $\boldsymbol{T b} / \tau$ & 1 & 2.718 & 3.695 & 4.463 & 5.119 & 5.699 & 6.226 & 6.711 & 7.164 & 7.59 \\
\hline $\boldsymbol{T d} / \tau$ & 0 & 1 & 2 & 3 & 4 & 5 & 6 & 7 & 8 & 9 \\
\hline $\boldsymbol{T e} / \tau$ & 1 & 2 & 2.5 & 2.888 & 3.219 & 3.51 & 3.775 & 4.018 & 4.245 & 4.458 \\
\hline
\end{tabular}

As it can be appreciated, the determination of the order $n$ and the time constant $\tau$ presents ambiguities: $w$ ith different parameters may be obtained different results. Other objective is, therefore, to avoid the inherent ambiguity of this method.

The Strejc method does not consider the possible presence of a pure delay in the identified process nor in the model. This deficiency is basic in order to use it as a predictor and should be solved in the algorithm.

\section{PROCEDURE FOR THE CALCULUS OF THE STREJC MODEL.}

The proposed algorithm to determine the Strejc model, implemented in MatLab, has the follow ing steps:

- Take a sample of the unit step response of the process $w$ ith constant time period: $y\left(t_{k}\right), k=1,2,3, \ldots, N$.

- Approximate the sample $y\left(t_{k}\right) w$ ith a polynomial $p(t)$ :

$$
p(t)=a_{m} t^{m}+a_{m-1} t^{m-1}+\ldots+a_{1} t^{1}+a_{0}
$$

- Choose the grade of the polynomial. This selection is accomplished increasing it from the unit until the error vector norm betw een the real output and the approach is less than a predetermined percentage of the maximum value of the output. It has been taken $1 \%$ as error percentage, generally resulting in a $5^{\text {th }}$ grade polynomial. The criteria for the election of the coefficients is the minimization of the quadratic error. In this work the POLYFIT function of MatLab has been used and it can be easily implemented in any language. In this application, only part of the response is considered: $y\left(t_{k}\right)$ w ith $t_{k} \in\left[t_{n}, t_{N}\right]$, w here $t_{r}$ is the pure delay estimated through some heuristic criteria, for instance, the period of time accounted from the beginning of the test until the output reaches $1 \%$ percent of ts new stationary value or maximum value.

- Calculate the inflexion point of the unit step response of the system using the second derivative of $p(t)$. This leads to a third grade polynomial (supposing $p(t)$ is fifth grade), one of its three solutions is the inflexion point time.

- Determine the inflexion point time finding which of the last three solutions of $p$ "' $(t)$ minimizes the absolute value of the function:

$$
\Delta^{2} y\left(t_{i}\right)=y\left(t_{i}\right)-2 y\left(t_{i}-1\right)+y\left(t_{i}-2\right)
$$

where $t_{i}$ are all possible real solutions of $p$ "'(t). 
- $\quad$ Calculate the parameters $T a, T b, T c, T d, T e$ y $\eta$ show $\mathrm{n}$ in figure 1 , and their relationamong themfor their use in the table 1, calculating the equation of the tangent line $y=m t+b$ of the unit stepresponse in the inflexion point $t_{\text {INFX }}$, remembering $m=p^{\prime}\left(t_{\text {INFX }}\right)$ and $b=p\left(t_{\text {INFX }}\right)-p^{\prime}\left(t_{\text {INFX }}\right) t_{\text {INFX }}$.

- Select the order of the transfer function $G(s)(1)$ that w ill approximate the real system. It takenas the maximum of the orders $n_{1}, n_{2}$ y $n_{3}$ given in the table 1 for the relations $T a / T b, T e / T b$ y $\eta$.

- Estimate the time constant $\tau$ of $G(s)$ using the order of the transfer function, table 2 and calculate four candidates.

- Calculate a fifth candidate from the mean of the other four.

- Choose the candidate that minimizes the quadratic error.

The whole procedure has been implemented in MatLab, therefore, for a real process it is only neededa sample of the unit step response from the plant, whose output $w$ ill be stored in the computer memory. Then it is obtained $G(s)$, used in the structure show $n$ in figure 2, know $n$ as Generalized Smith Predictor.

\section{GENERALIZED SMITH PREDICTOR}

The scheme for the proposed control is show $n$ in figure 2 .

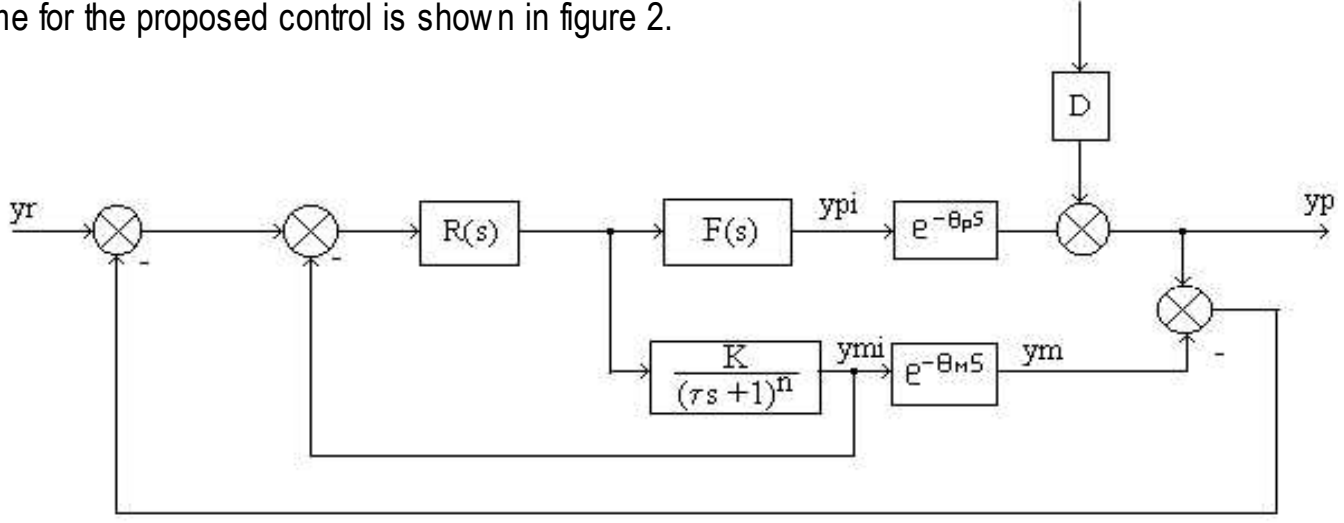

Figure 2. Generalized Smith Predictor Control Scheme.

The concept is similar to the proposed in [3]. The feedback inner loop of the system show $\mathrm{n}$ in figure 2 uses the model suggested by Strejc (1). The difference betw een both methods is the higher accuracy reached by a higher order versus a first order model. The noxious delay effect is diminished by the feedback inner loop because the control action anticipates as a result of the prediction given by the delay free plant model.

It is not an objective of this w ork to give a theoretical basis for the proposed scheme, but to show its performance through some simulations and one real implementation.

\section{SIMULATIONS}

The follow ing plant has been used to compare the performance of the Strejc model versus theclassical Smith one:

$$
P(s)=\frac{1}{80 s^{2}+18 s+1}
$$

with a delay of 200 seconds. The controller is a basic PI scheme, and its parameters w ere adjustedin order to reach the best performance. There has not been considered any kind of noise. 
The unit impulse response of the plant is show $\mathrm{n}$ in figure 3. Its approximation by a first and second order model are show $\mathrm{n}$ in figures 4 and 6 , respectively. The proposed algorithm has calculated the models. The difference in the accuracy betw een both approximations is the basis for the higher performance of the control system in the generalized case. The errors for the classical and generalized approximations are show $\mathrm{n}$ in figures 5 and 7 , respectively.

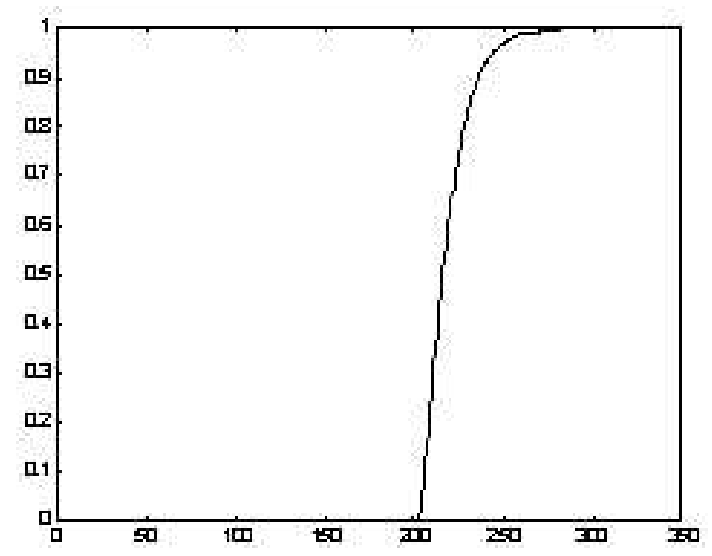

Figure 3. Real System step unit response.
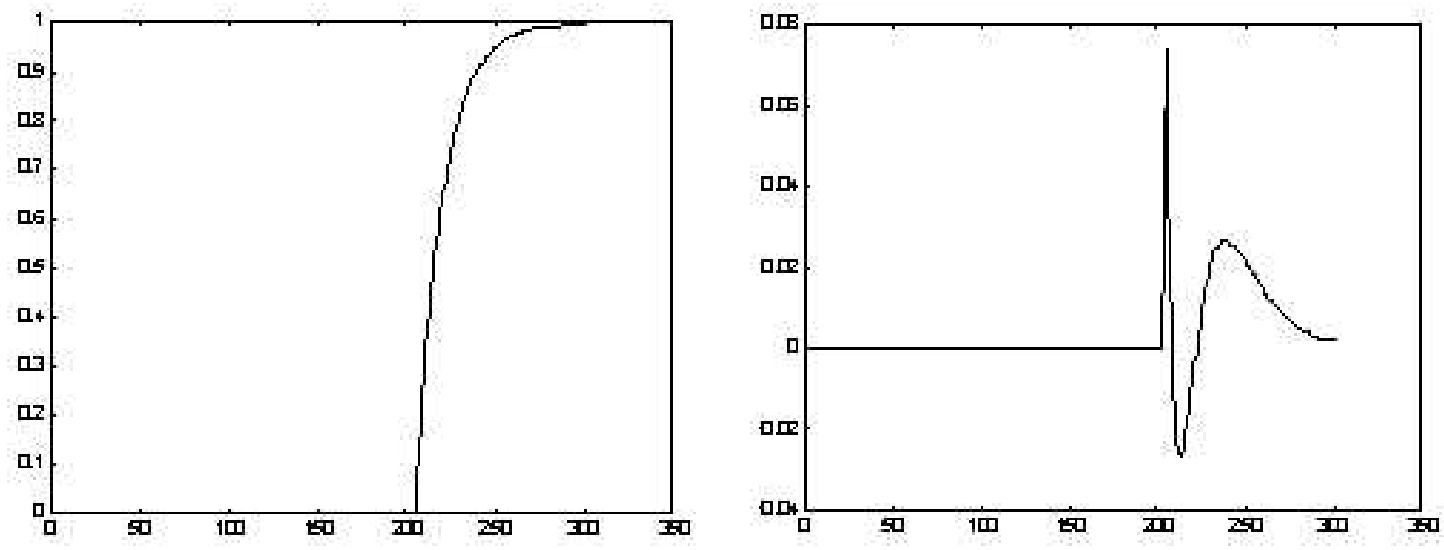

Figure 4 and 5. Classical approximation and its error.
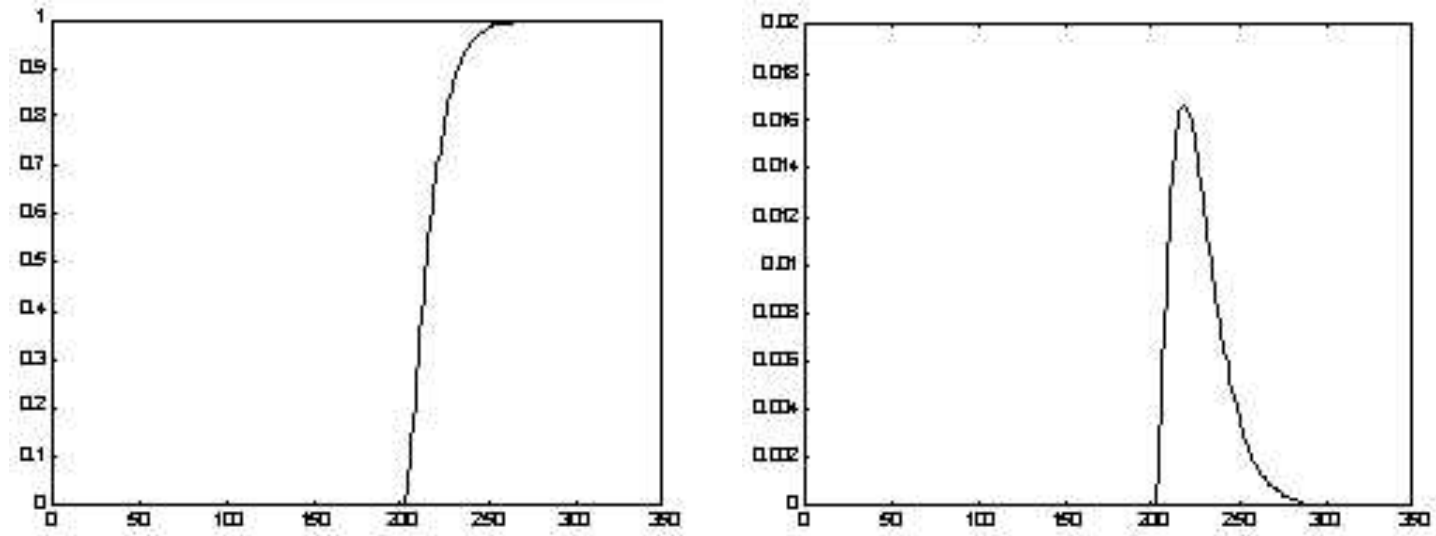

Figure 6 and 7. Generalized approximation and its error. 


\section{RESULTS}

The result, $w$ hen the prediction has not been applied in the control loop is show $\mathrm{n}$ in figure 8. Obviously, the result is unstable. The reference is a pulse train and it has been show $\mathrm{n}$ in the same figure.

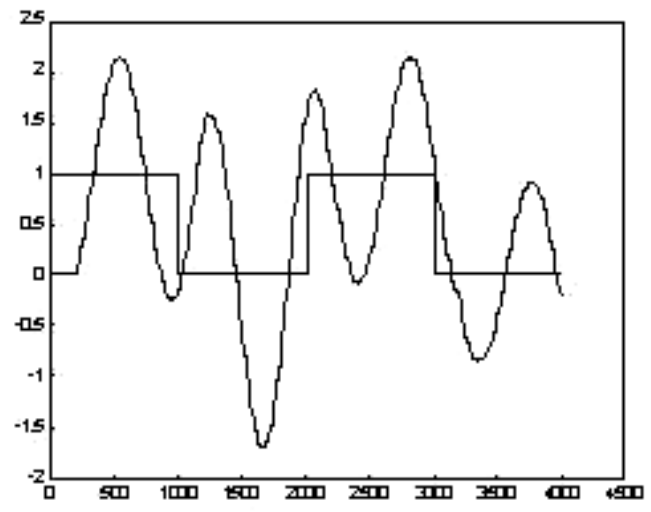

Figure 8. Control without Predictor. Time in seconds.

Figure 9 show s the result when a classical Smith Predictor is used in the feedback loop. Again, the controller parameters $w$ ere adjusted in order to reach the best performance.

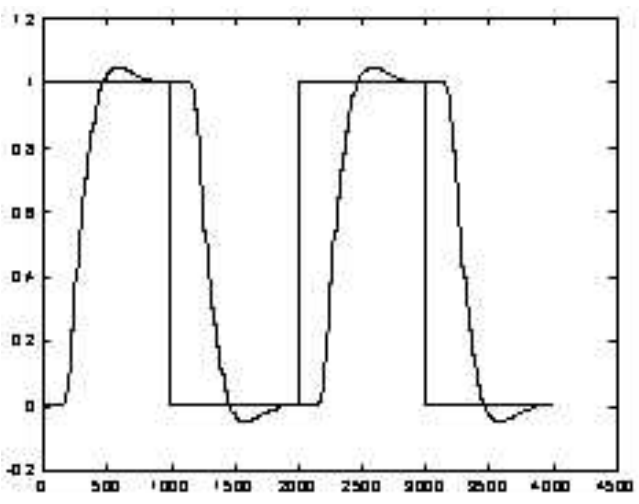

Figure 9. Control with Classical Smith Predictor

Figure 10 shows the result when a Generalized Smith Predictor has been used. The controller parameters were similar to the previous Classical Smith. It is relevant to notice that there is no over impulse.

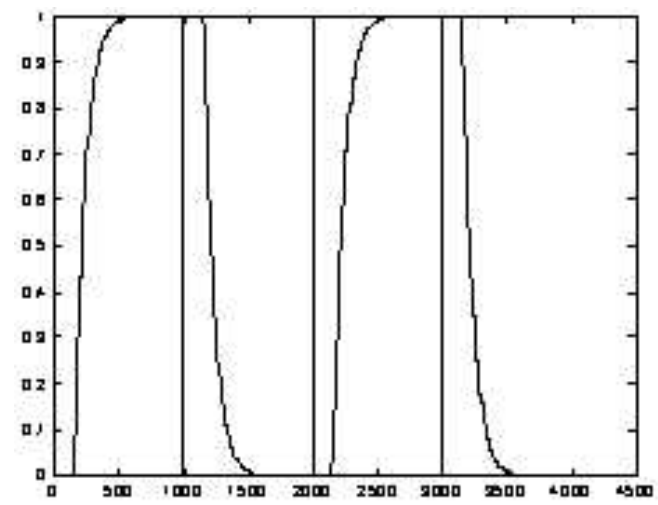

Figure 10. Control with Generalized Smith Predictor. 


\section{APPLICATION}

The same principle is applied to a Biomass Combustor, described in section 7.1. In section 7.2 the methodology for the treatment of the data obtained from the Combustor noisy acquisition is presented. The application of proposed mehodology is presented in section 7.3.

\subsection{Biomass Combustor}

The system called Biomass Combustor is a project undertaken in CIATEQ A. C. Basically, it consists of a cyclonic chamber currently operated $w$ ith dry sugar cane bagasse as combustible, how ever, it can operate $w$ ith other types of biomass. The goal is to give to some industries an alternative systemw itha higher efficiency in combustion.

The air is fed into the chamber using tw o compressors, and the combustible using a speed controlled electric motor. The initial ignition is started out by an external torch that is removed once the combustion has started.

Now adays, the optimization of the operation it is studied. Another goal of this w ork is the identification of noisy signals presented in the identification and control system.

There are some sensors to study the Combustor performance:

- Tw o Venturi differential pressure sensors that provide the reading for the air mass caudal calculation.

- The combustible mass caudal is calculated through Mass Caudal versus Speed Variator Curves, using the reading of a speed sensor in the combustible feeder motor.

- Nine sensors for temperature: 5 thermocouples and 4 RTD.

The two air pressure, the speed variator and the temperature sensors are the most important for the objective of this work. The first three sensor are considered as inputs and the last two sensors as outputs. Therefore, the system is multivariable, w ith three inputs and tw o outputs.

\subsection{Signal Treatment}

Figure 11 show $s$ the output temperature signal w hen the system has been excited by a unit step change in the primary air. The obtained response is the typical one for a first order system with delay and additive noise. The last one is due to various factors, as the $w$ ay the biomass enters the chamber (as small as dust particles or in the form of little packages), the temperature environment, the thermocouple sensor measurement, among others.

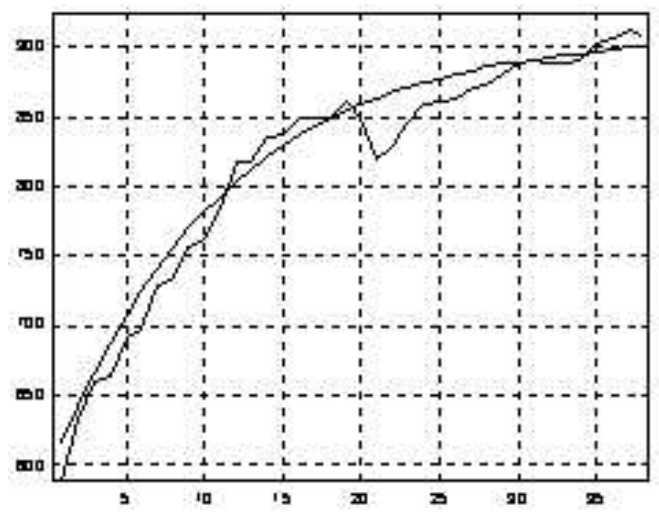

Figure 11. Combustor unit step response and predictor response. 
A modified least-square algorithm has been applied for the model identification starting out $w$ ith the signal show $\mathrm{n}$ in figure 11 and filtering the additive noise. The prediction response is show $\mathrm{n}$ in the same figure, and is recognized from the real one because its noiseless appearance.

The resulting transfer function after the application of the described algorithm is as follow s:

$$
G(s)=\frac{898}{\operatorname{den}(s)}
$$

where the denominator is $10^{\text {th }}$ grade $w$ ith the follow ing coefficients:

$$
[1.156 \mathrm{e} 6,2.862 \mathrm{e} 6,3.189 \mathrm{e} 6,2.105 \mathrm{e} 6,9.121 \mathrm{e} 5,2.71 \mathrm{e} 5,5.59 \mathrm{e} 4,7908,734.2,40.39,1]
$$

\subsection{RESULTS}

After the application of the technique, the results are show $\mathrm{n}$ in figure 12.

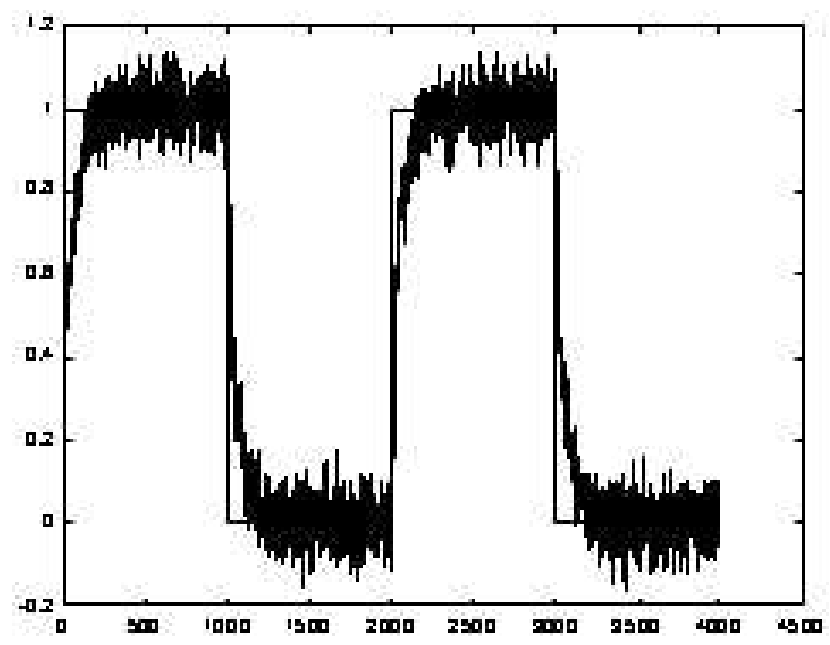

Figure 12. Generalized Predictor Control of the Combustor.

\section{CONCLUSIONS}

The Smith Predictor Control scheme has show $\mathrm{n}$ to be efficient if the plant has a pure delay when the time constants are not too high. How ever, when this condition is not accomplished, the prediction could not be accurate enough to obtain an adequate control performance. The same idea, by using a higher order predictor as the one proposed in this w ork, might enhance the control system performance; this has been obtained because the prediction is improved and the error decreases very fast The cost in the calculus is practically no affected if it is compared in complexity $w$ ith the classical Smith Predictor. Future w ork comprises the identification of the plant w ith an Artificial Neuronal Netw ork to enlargethe universe of feasible non linear ties that can easily be approximated $w$ ith this tool.

The application of the presented methodology is very simple and accurate. Permits its use in the industrial field, as paper factory, thermal and other types of processes involving control and sensors separated by mobile bands, or sub processes that adds a delay time between the adjust and the resulting output. 


\section{REFERENCES}

[1] Aguado A., 2000, Temas de Identificación y Control Adaptable, Edición del ICIMAF, La Habana.

[2] Strejc V., 1960, Approximate determination of the control characteristics of an aperiodic response process, utomatisme.

[3] Smith, O.J.M. 1959, A controller to overcome dead time. ISA J., Vol. 6 (2), page 28.

[4] Palmer, Z. J., Shinnar, R. 1979, Design of Sampled data controllers, Ind. Eng. Chem. Process Des. Dev., V. 18 NN$^{\circ} 1$. 
Authors Biography

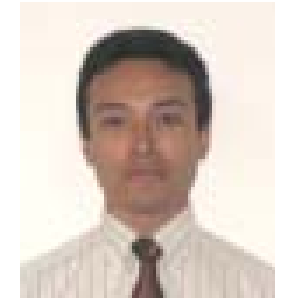

Raúl Ramírez López.

Born in Mexico City, June 26, 1963. He w as graduated as Communications and Electronic Engineer in National Polytechnic Institute (IPN) in 1986. He studied Electrical Engineering M. S. w ith specialty in Automatic Control in Research and Advanced Studies Center of IPN (1985-1987). Actually is Candidate to PhD in Automatic Control in the Queretaro Autonomous University. Is Researcher in the CIATEQ AC since 2000. He has been professor in Metropolitan Autonomous University (1989-1994), in the IPN (1990), in the Queretaro Technologic University (1994-1996), in the Monterrey Superior Studies Technological Institute, Campus Queretaro (1997), in the UAQ (1997-1998), and in the Queretaro Technological Institute (2000). Is author of 3 papers in International and 3 of national Congress and in 2 international magazines. His main interest theme is Stochastic Systems.

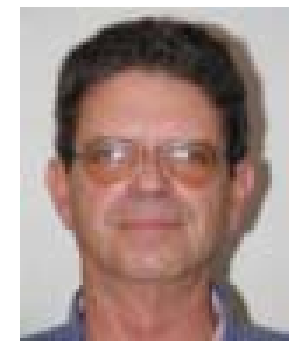

Alberto Aguado Behar

Was born in Matanzas, Cuba, in September 9, 1941. Graduated as Electrical Engineer especialized in Automatic Control in 1966, in the Havana Higher Politechnical Institute. He obtained the PhD degree in Technical Sciences in the Technical Cybernetic Institute of Bulgary, in 1976. He works as a senior researcher in the Institute of Cybernetics, Mathematics and Fisics of Havana and in the Higher Politechnical Institute of Havana as Titular Profesor. In the las years he has lectured invited conferences and courses in the Universidad Autónoma de Querétaro and in the Instituto Politécnico de Pachuca, México as w ell as in the Politechnical Universities of Valencia, Valladolid and Cataluña in Spain. His main research themes in the last years has been Identification and Predictive-Adapative Control and Inteligent Control. He is the main author of more than 80 papers about diferent control themes and of two books edited in Havana. 